\title{
Biochar-just a black matter is not enough
}

\author{
Andreas Hornung $^{1,2,3}$ (D) Fabian Stenzel $^{1} \cdot$ Jan Grunwald ${ }^{1}$
}

Received: 14 October 2020 / Revised: 17 December 2020 / Accepted: 4 January 2021

(C) The Author(s) 2021

\begin{abstract}
What differs biochar from charcoal? The simple answer is that biochar is a carbon-rich product obtained from the thermal decomposition of organic material, at the presence of no or only a bit of oxygen. In principle, the production of biochar is comparable to the production of charcoal, one of the oldest and most established processes developed by mankind. While charcoal is made traditionally from wood, biochar can be based on a wide range of biomass and biomass residues. However, a variety of technologies for the production of biochar has been developed in recent years. The technologies are based on pyrolysis, gasification, or hydrothermal carbonization and are ranging from simple units, like heated steel drums to full automated and controlled processes. Therefore, the obtained products have tremendous differences in its properties and resulting qualities. The quality defines the field of application. To obtain the required quality for each application, the right process must be applied. Consequently, it is not enough only to enrich the carbon content by thermal decomposition of organic material. The production of tailor-made biochar for specific high added-value application is much more complex. In addition, side products like liquid biofuels make business cases stronger. If it is done in the right way, biochar production combined with advanced biofuels can be an economic solution to overcome the problems of climate change. "So for the future of mankind, this black matter might give the light at the end of the tunnel."
\end{abstract}

Keywords Biochar · Thermochemical conversion · Certification · Legal regulation · EN-biofuels · Carbon sequestration

\section{Introduction}

Biomass stores carbon in a huge quantity of about 650 billion tonnes worldwide [1]. This is the same amount of worldwide anthropogenic $\mathrm{CO}_{2}$ emissions of about 65 years [2]. The biggest proportion of about $82 \%$ is stored in wood. However, $\mathrm{CO}_{2}$ is also released by natural processes, for example, by aerobe degradation of harvested or dead biomass. A longterm storage of carbon or respectively $\mathrm{CO}_{2}$, which was naturally captured by wood during its growth phase, is possible by the conversion of wood into biochar. To make the biochar

Andreas Hornung

andreas.hornung@umsicht.fraunhofer.de

$1 \quad$ Fraunhofer Institute for Environmental, Safety, and Energy Technology (UMSICHT), An der Maxhütte 1, 92237 Sulzbach-Rosenberg, Germany

2 Faculty of Engineering, Department of Chemical and Biological Engineering, Friedrich-Alexander University Erlangen-Nuremberg (FAU), Schlossplatz 4, 91054 Erlangen, Germany

3 School of Chemical Engineering, University of Birmingham, Edgbaston, Birmingham, West Midlands B15 2TT, UK production more sustainable, the range of feedstock should be extended to biogenic residues like agricultural residues, sewage sludge, digestate from biogas production, residues from food industry (e.g., brewer spent grain), or residues from modern processes like ethanol production from straw and macroalgae. These materials are almost by-products and need to be used in a valuable way. However, the production of biochar as the only product of a process is almost too expensive. To close the bill, side products or additional valuable products are required. Those products can be liquids, in best case fuels and green hydrogen.

The biochar topic became famous within the last 10 to 15 years. Especially the investigations of the Terra Preta de Indio in the Amazonian region increased the interest in biochar $[3,4]$. But the question is: What is biochar exactly? The simple answer is that biochar is a carbon-rich product obtained from the thermal decomposition of organic material, at the presence of no or just a bit of oxygen [3]. As we can see in principle, the production of biochar is comparable to the production of charcoal, one of the oldest and most established processes used by mankind. But what is the difference between both? It is the feedstock! Charcoal is derived from wood only, whereas biochar is derived from any kind of 
biomass. However, a clear definition of biochar does not exist up to now. A part of the scientific community applies the term biochar only for carbonized material which is used in soil. Another part applies this term only for carbonized material which is produced by pyrolysis. In addition, two new terms were introduced, since the research activities in the field of hydrothermal carbonization (HTC) increased. These terms are pyrochar from pyrolysis and hydrochar from HTC [5]. Therefore, it becomes obvious that biochar is not a single substance; it is rather a group of substances with a broad range of properties [6]. Consequently, biochar can be used for a variety of applications, exemplarily named soil improver, additive in animal fodder, activated carbon, or additive in construction material [7]. In addition, biochar derived from biomass by pyrolysis can be also used as catalyst or respectively catalyst carrier [8]. But for each application, certain properties of the biochar are required. If biochar is used in a product and not energetically, the carbon is sequestered over the lifetime of the product. This reduces $\mathrm{CO}_{2}$ from the atmosphere, which was taken up by the biomass during its growth phase. Therefore, it is a potential measure to reduce global warming [9].

Biochar is not always the same, even if it is almost always black matter. However, the properties depend on a variety of parameters like feedstock, processes, and process conditions. Legal and technical requirements have to be fulfilled for each biochar application. This study gives an overview of production, characterization, as well as possible applications of biochar and their market potentials. Standards and certificates are presented to guarantee the proper quality, because "just a black matter is not enough."

\section{Feedstock for biochar production}

For biochar production, almost any kind of biomass feedstock can be used. Especially, the use of organic waste or residues brings a huge benefit, because this material does not need to be cultivated separately for biochar production, as it is a byproduct. However, the properties of the biochar are influenced by the kind of feedstock. One aspect is the organic

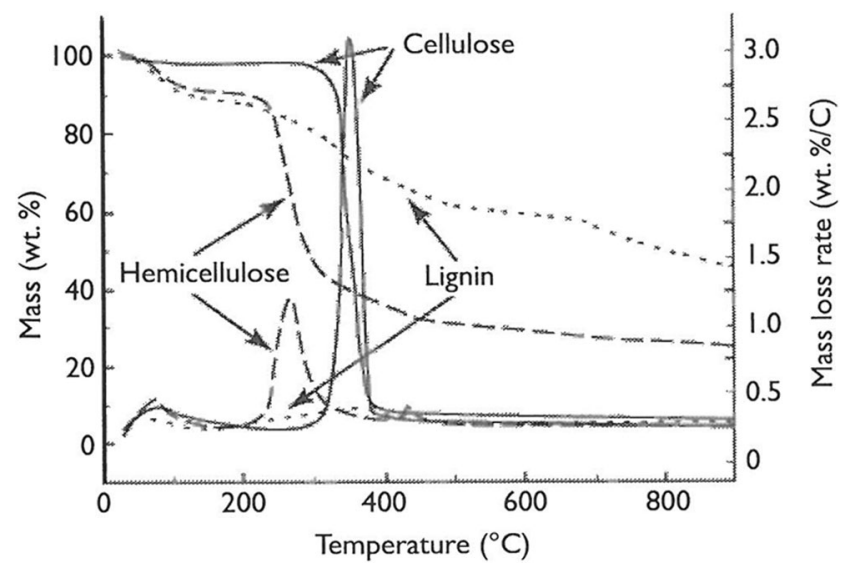

Fig. 1 TGA analysis of the pyrolysis of cellulose, hemicellulose, and lignin [10]

composition. The shares of cellulose, hemicellulose, and lignin influence the yield of biochar. Figure 1 shows the decomposition of these three components. At the beginning, hemicellulose starts to decompose by increasing temperature up to $315^{\circ} \mathrm{C}$. Cellulose starts its decomposition at about $300^{\circ} \mathrm{C}$ and is almost completed at $400{ }^{\circ} \mathrm{C}$. While the decomposition of lignin starts at around $160^{\circ} \mathrm{C}$ leading to a weight reduction of around $40 \mathrm{wt} \%$ of the original mass. Therefore, the yield of biochar is mainly influenced by the share of hemicellulose and lignin [10].

The ash content of the feedstock influences the biochar yield indirectly, too, as almost all inorganic compounds remains in the char [11]. On the other hand, it reduces the share of carbon in the biochar. Also the heating value of feedstock with high ash content is usually lower. The following table shows exemplarily the properties of possible feedstocks for biochar production. It is shown that the heating value corresponds to the carbon content and the ash content. All values presented in Table 1 are referred to total dry matter content. However, some of the feedstocks have originally a high water content. Sewage sludge directly from a waste water treatment plant has more than $90 \%$, as well as digestate from biogas plants and brewer's spent grain have more than $80 \%$ of water content for instance [12-14]. Depending on the downstream conversion process, the feedstocks have to be pretreated that
Table 1 Feedstocks for biochar production and its properties

\begin{tabular}{llllll}
\hline Parameter & Unit & Sewage sludge & Digestate & Brewer's spent grain & Wood \\
\hline Carbon & wt\% (DM) & 25.0 & 41.6 & 48.6 & 45.0 \\
Hydrogen & wt\% (DM) & 4.3 & 5.1 & 6.9 & 6.4 \\
Nitrogen & wt\% (DM) & 3.6 & 1.6 & 4.3 & 0.1 \\
Sulfur & wt\% (DM) & 0.9 & 0.3 & 0.5 & 0.1 \\
Oxygen* & wt\% (DM) & 19.7 & 31.6 & 36.2 & 47.8 \\
Ash & wt\% (DM) & 46.5 & 8.7 & 3.5 & 0.6 \\
Lower heating value & $\mathrm{MJ} \cdot \mathrm{kg}^{-1}(\mathrm{DM})$ & 8.1 & 15.8 & 20.5 & 17.8 \\
\hline
\end{tabular}

*Calculated by difference 
means dewatering and drying to adjust the required water content and possible milling and pelletization to adjust the particle size. On the other hand, wood is a relatively dry feedstock. Fresh harvested material has a water content of about $50 \%$ [15]. Therefore, an appropriate pretreatment for fresh wood is chopping and drying.

\section{Processes}

As mentioned above, the production of charcoal is one of the oldest known processes of mankind. For its production, a pile of wood logs is built and covered by soil to avoid oxygen intrusion. Volatiles are emitted to the environment, and produced liquids like pyroligneous acid, for instance, are seeped into the ground. Today, modern reactors are developed to produce biochar. They fulfill environmental standards, and some of them use the side products like gases and liquids to improve the whole process efficiency. The processes can be divided into the following categories.

\subsection{Hydrothermal carbonization}

The HTC is best suitable for feedstock with a high moisture content, because the feedstock is mixed with water in a typical solid to water ratio of 1:6 to obtain a suspension [16]. Therefore, sewage sludge and digestate are suitable feedstocks with regard to the water content. This suspension is fed into the reactor where the conversion of the biomass takes place. The operating conditions are $180-260^{\circ} \mathrm{C}$ and $15-60$ bar. The residence time of the feedstock is in a range of $2-16 \mathrm{~h}$. The obtained product is a suspension with carbon-enriched particles - the biochar - and the process water (see Fig. 2). The dewatering of the produced biochar is easier compared to the feedstock [17]. The disadvantage of the HTC is the huge quantity of process water with a chemical oxygen demand (COD) of about 30,000 to $50,000 \mathrm{mg} / 1$ [18]. If the solid content in the suspension is adjusted up to $20 \% \mathrm{DM}$, COD up to $100,000 \mathrm{mg} / \mathrm{l}$ is possible. The COD consists of a variety of organic compounds like aldehydes, phenols, ketones, esters, and organic acids. Among the dry matter content of the suspension, the operating temperature of the HTC process influences the concentration of the COD as well. It increases with an increase of the temperature. From a sufficient high temperature, the COD concentration begins to decrease, because of re-polymerization of the organic compounds [19]. Some approaches are focused on the recovery of the organic compounds as valuable products. However, at the current state of development, this water has to be treated before discharge [17]. For the typical ratio of dry biomass to water and a typical biochar yield of 50\%, 12 tonnes of water are needed to obtain 1 ton of biochar [16]. Finally, the produced biochar has to be dewatered and dried prior to its energetic use.

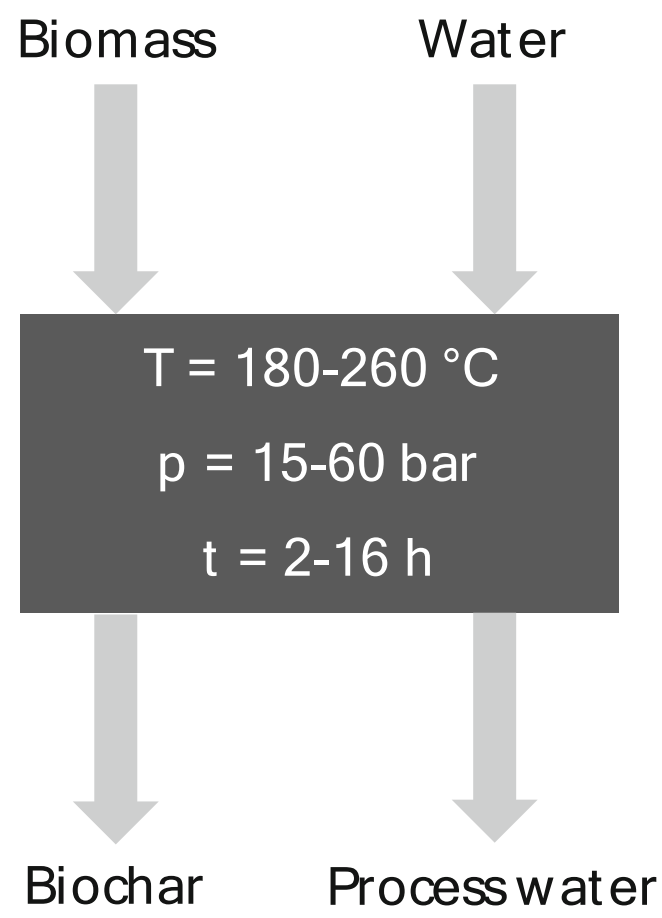

Fig. 2 Block diagram of hydrothermal carbonization

As mentioned above, a very famous application of HTC is the treatment of sewage sludge, because of its wet nature. One of the main benefits is the improvement of the dewatering of the sludge after HTC. However, not all pollutants in the sewage sludge are destroyed. For example, pharmaceutical residues remain partly in the hydrochar [20]. Furthermore, the process water from HTC process cannot be recirculated, because water is permanently fed into the reactor as part of the wet feedstock. These large quantities of process water have to be treated. In the case of sewage sludge treatment, the HTC plant should be installed directly on site of a waste water treatment plant. If digestate shall be treated by HTC, the process water can be used to mash the substrate for the biogas plant. However, the nitrogen content should be considered, because high nitrogen concentrations can inhibit the fermentation process. Known market player are Terra Nova Energy, SunCoal, AVALON Industries, Ingelia, and Avello Bioenergy.

\subsection{Pyrolysis}

Pyrolysis can be divided into three subcategories - fast, intermediate, and slow pyrolysis. However, all have one thing in common. The operation is without air or respectively oxygen [21]. In Fig. 3, all three types of pyrolysis are shown. The feedstock is dry biomass. Wood is a very common feedstock. As mentioned above, only drying and chopping are required. But also wet feedstocks, like sewage sludge, digestate, or brewer's spent grain, can be used after dewatering and drying. The products obtained are gas, liquid, and biochar. The 
Fig. 3 Block diagram of fast (left), intermediate (middle), and slow (right) pyrolysis

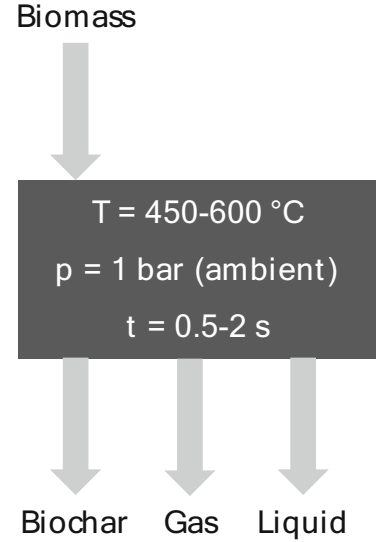

distribution of the products depends on the operation parameters, like maximum operation temperature, heating rate, and the residence time.

The objective of the fast pyrolysis is to maximize the yield of the liquid product. Therefore, very high heating rates up to $1000{ }^{\circ} \mathrm{C} / \mathrm{s}$ are applied. After a residence time of only a few seconds $(0.5-2 \mathrm{~s})$, the vapor phase is cooled down very fast to reduce further thermal decomposition. To realize the high heating rates, the feedstock has to be grounded down to a particle size of a few millimeters to a few micrometers. For the fast pyrolysis of woody biomass, up to $75 \%$ of liquid can be obtained [21]. But the liquid has a high water content of $20-30 \mathrm{wt} \%$ and a high oxygen content of about $39 \mathrm{wt} \%$. In addition, the total acid number (TAN) is in a range of a few hundred $\mathrm{mg}_{\mathrm{KOH}} / 1$, which is quite high [22]. One of the most famous representatives of the fast pyrolysis is the bioliq ${ }^{\circledR}$ process developed by the Karlsruher Institute of Technology (KIT), which is operated in pilot scale onsite the KIT campus. Further representatives are btg, ENSYN EMERGENT waste solutions, and Avello Bioenergy.

Slow pyrolysis is one of the oldest processes for biomass conversion. The focus is on a maximum yield of biochar. A typical "technology" for the application of this process was and sometimes still is the charcoal pile. In an industrial scale, a retort is used. The biomass is treated at a temperature of about $500{ }^{\circ} \mathrm{C}$ for hours or days. In addition to the biochar, some liquids like acetic acid or alcohols are produced as well, but usually the vapor phase is used for heat supply to the process. For the feedstock, no special pretreatment is needed. The moisture should be below $40-50 \mathrm{wt} \%$, and the particle size can range from briquette to whole logs [21]. A famous market player here is proFagus. They apply the Degussa process in a large retort.

Between fast and slow pyrolysis, the intermediate pyrolysis takes place. The residence time of the feed is in a range of a few minutes, and heating rates of $200-300{ }^{\circ} \mathrm{C} / \mathrm{min}$ are applied. The process usually runs at temperatures of $400-500{ }^{\circ} \mathrm{C}$. To realize these process conditions, the moisture content of the feedstock is limited to about $40 \mathrm{wt} \%$, and the particle size is

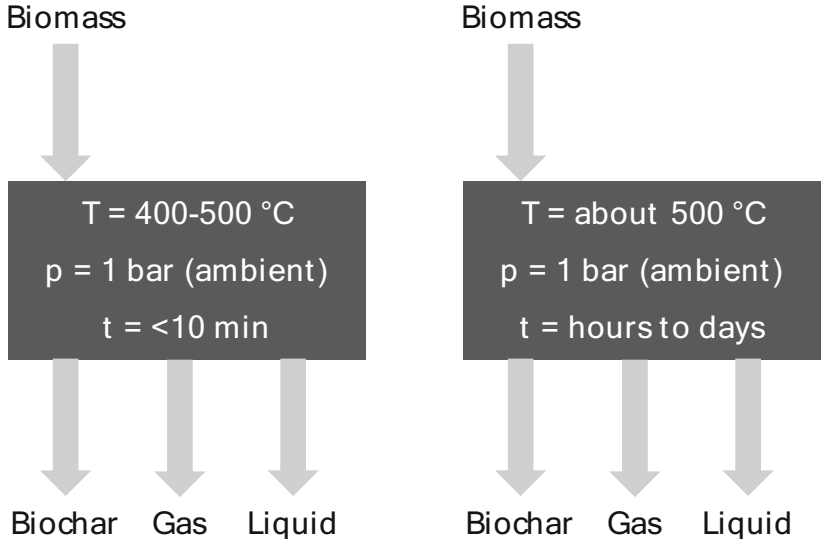

compared to coarse shredded, chopped, or briquetted material. Regarding the product yields, intermediate pyrolysis is between fast and slow pyrolysis as well. Compared to fast pyrolysis, the liquid yield is a little lower, but therefore, the biochar yield is higher. Compared to slow pyrolysis, it is the opposite [21]. A further development of the intermediate pyrolysis is the Thermo-Catalytic Reforming (TCR $®)$. It is a two-step process where intermediate pyrolysis is coupled with a reforming step. This increases the product quality drastically [23]. The degree of carbonization is quite high compared to other carbonization processes, but also the liquid quality is far better compared to fast pyrolysis. The organic phase can be separated easily from the water phase to obtain an oil with heating value of more than $30 \mathrm{MJ} / \mathrm{kg}$ instead of 13-18 MJ/ $\mathrm{kg}$. Furthermore, the total acid number (TAN) is in a range of $5 \mathrm{mg}_{\mathrm{KOH}} / \mathrm{g}$ and therefore quite lower compared to the oil from fast pyrolysis [22]. In addition, the TCR®-oil is thermal stable and therefore distillable and miscible with fossil fuels [23].

The most famous company which offers intermediate pyrolysis is PYREG. However, systems are also offered by WSE and Sea Marconi. The further developed Thermo-Catalytic Reforming is offered only by Susteen Technologies GmbH.

\subsection{Gasification}

In contrast to pyrolysis, the main product of the gasification is the synthesis gas and not the biochar. The char is rather a byproduct, and because of the very poor carbon content, it is almost not considered as a char. Furthermore, air and/or steam is added as gasification agent to the process with an equivalence ratio between $0<\lambda<1$. The process temperature ranges from 700 to $1400{ }^{\circ} \mathrm{C}$. Therefore, the main components of the product gas are carbon monoxide, hydrogen, and carbon dioxide. But also tar can be formed during the gasification process. The content can increase up to $150 \mathrm{~g} / \mathrm{m}^{3}{ }_{\mathrm{N}}$ depending on gasification process. A second issue is the particulate matter in the gas. Concentrations up to $100 \mathrm{mg} / \mathrm{m}^{3}{ }_{\mathrm{N}}$ are measured. Both have to be removed or respectively reduced before the gas is converted in a combustion engine. If air is used as gasification 
agent, a significant share of nitrogen is present in the gas as well, which leads to a dilution of the synthesis gas and a reduction of the heating value (Fig. 4) [24].

\section{Characterization of biochar}

\subsection{Degree of carbonization}

The objective of all the carbonization processes is to increase the carbon content in the product. This is combined with a separation of oxygen and hydrogen, while the ash remains in the solid phase. Depending on the process type and operating conditions, the carbonization happens in different intensities. The intensity of carbonization is also called the degree of carbonization. It is measurable with the molar ratio of $\mathrm{O}: \mathrm{C}$ and $\mathrm{H}: \mathrm{C}$ and is shown in the van Krevelen chart (see Fig. 5). The van Krevelen chart was originally developed to show the path of the natural carbonization of fossil fuels. However, results have shown that the carbonization of biomass to biochar follows the same pathways. Therefore, the van Krevelen chart is suitable to compare the degree of carbonization between biochars derived from different processes [26].

Additionally opaque areas are implemented in Fig. 5 to show the variety of hydrochars, pyrochars, and chars from

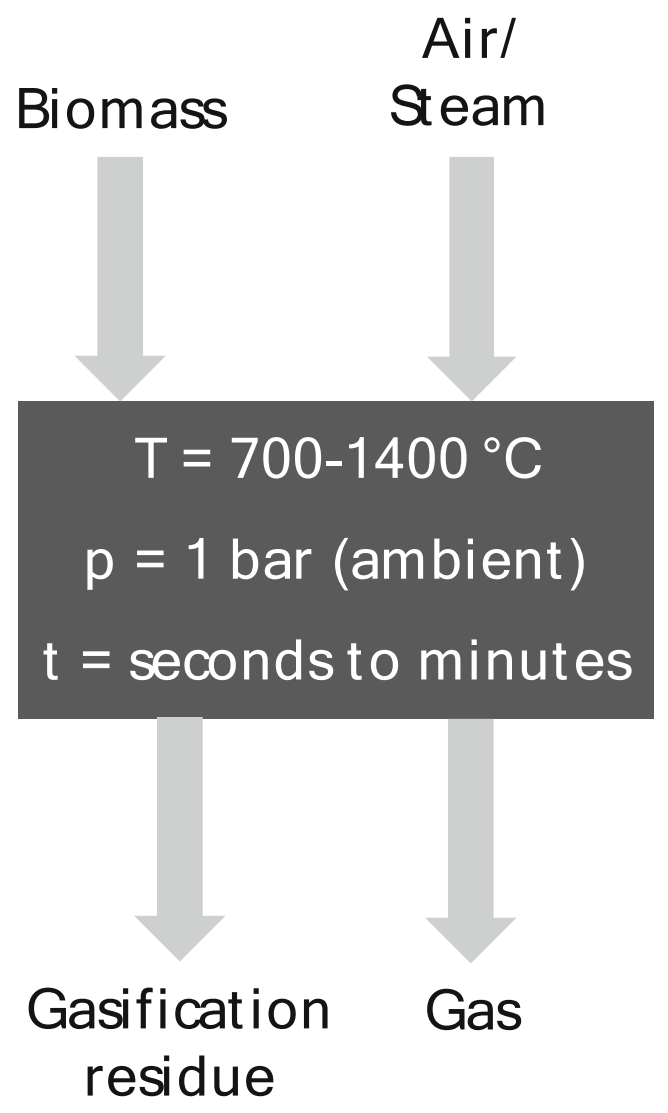

Fig. 4 Block diagram of gasification

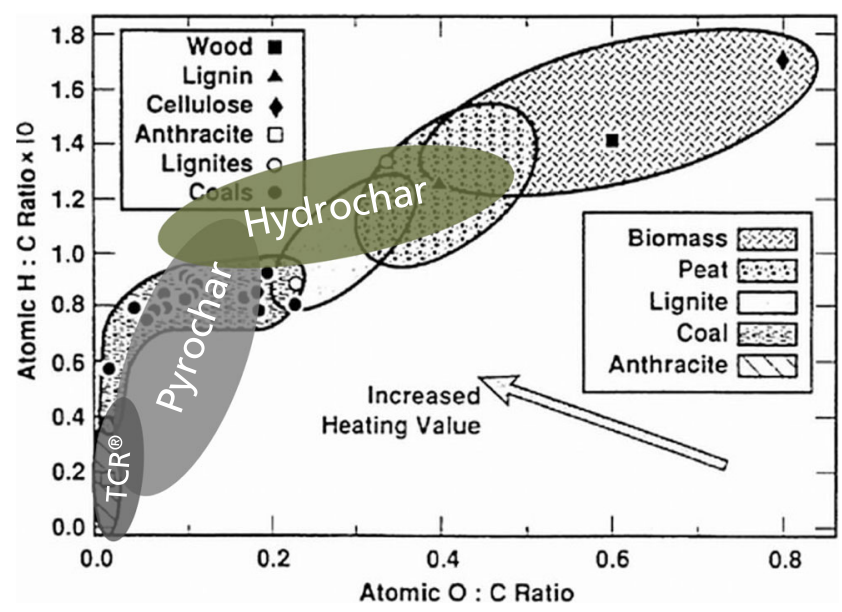

Fig. 5 Areas of hydrochar, pyrochar, and TCR $®$-char are shown in van Krevelen diagram [25] (adapted) values from [26-28]

the TCR $®$-process based on data from [26-28]. It is shown that chars from HTC show the lowest degree of carbonization. That means the hydrogen and oxygen content is higher compared to pyrochars and TCRß-chars. The lowest contents of oxygen and hydrogen are observed in TCR ${ }^{\circledR}$-chars. Therefore, the lowest ratios of $\mathrm{O}: \mathrm{C}$ and $\mathrm{H}: \mathrm{C}$ are obtained. The lower the O:C ratios, the higher is the stability of the char in soil. Additionally, it becomes harder for microorganisms to metabolize the char. With regard to the O:C ratio, Spokas divided biochars into three groups: $<0.2,0.2-0.6$, and $>0.6$. In the same order, the following half-life times are assigned: $>$ 1000 years, $100-1000$ years, and $<100$ years [6]. But further analysis methods should be applied to verify the half-life times, because hydrochars show shorter half-life-times as predicted by the O:C ratio [29]. However, biochars produced by pyrolysis or respectively by TCR® have the potential to withdraw carbon from the atmosphere for more than 1000 years, if it is used as a soil improver, for example.

Examples of TCR®-chars are also shown in Table 2. They are derived from the feedstocks mentioned in Table 1. The calculated $\mathrm{O}: \mathrm{C}$ and $\mathrm{H}: \mathrm{C}$ ratios fit to the TCR ${ }^{\circledR}$ area shown in Fig. 5. It was also observed that the $\mathrm{O}: \mathrm{C}$ ratio increases with an increase of the carbon content and respectively with a decrease of the ash content. It is possible that oxygen is bound to carbon as functional groups on the surface of the char [30]. A further analysis of the surface with Diffuse Reflectance Infrared Fourier Transform Spectroscopy (DRIFTS), for example, can bring more detailed results on that. This method enables the analysis of strong absorbing surfaces.

The ash content influences the composition of the biochars in general, because almost all inorganics remain in the char. Therefore, the ash content increases during the carbonization process. This becomes obvious, if the ash contents of the feedstocks in Table 1 are compared to the ash contents of the biochars in Table 2. 
Table 2 TCR®-chars derived from biogenic residues [28]

\begin{tabular}{llllll}
\hline Parameter & Unit & Sewage sludge & Digestate & Brewer's spent grain & Wood \\
\hline Carbon & wt\% (DM) & 22.2 & 64.0 & 72.6 & 89.8 \\
Hydrogen & wt\% (DM) & 0.9 & 1.0 & 0.1 & 2.2 \\
Nitrogen & wt\% (DM) & 2.0 & 1.4 & 4.6 & 0.3 \\
Sulfur & wt\% (DM) & 1.0 & 0.5 & 0.4 & 0.1 \\
Oxygen* & wt\% (DM) & 0.0 & 0.7 & 4.9 & 4.5 \\
O/C & - & 0.00 & 0.01 & 0.05 & 0.04 \\
H/C & - & 0.49 & 0.19 & 0.02 & 0.29 \\
Ash & wt\% (DM) & 74.4 & 32.0 & 17.5 & 3.1 \\
Lower heating value & MJ.kg ${ }^{-1}(\mathrm{DM})$ & 8.2 & 23.0 & 26.0 & 34.4 \\
\hline
\end{tabular}

*calculated by difference

\subsection{Surface analysis}

If biochar shall be applied as adsorbents, the surface area and structure are very important. The surface of biochar can be divided in inner and outer surface area, whereas the inner surface area is almost larger than the outer surface area. The inner surface area is defined by the pore system in the biochar. It consists out of micro, meso, and macro pores. The size of the surface area can range from a few square meters per gram to up to 2000 or $3000 \mathrm{~m}^{2} / \mathrm{g}$. The surface area depends on the process temperature and if the biochar is subsequently activated or not (Fig. 6) [31].

Figure 7 shows the development of the pore volume in \% and the surface area in $\mathrm{m}^{2} / \mathrm{g}$ of lignite depending on the process temperature. Both increase with increasing process temperature. It is noticeable that from 600 to about $800{ }^{\circ} \mathrm{C}$, both the pore volume and the surface area increase very fast. Therefore, experiments with the TCR®-reactor were carried out at Fraunhofer UMSICHT to investigate the development of the pore volume depending on the temperature in the postreforming unit. The results are shown in Fig. 8, where the pore volume is plotted versus pore size distribution.

It is obvious that the pore volume increases with an increase of the post-reforming temperature. Furthermore, the share of the fine pores increases with an increasing temperature as well. For the last trial, water was additionally injected

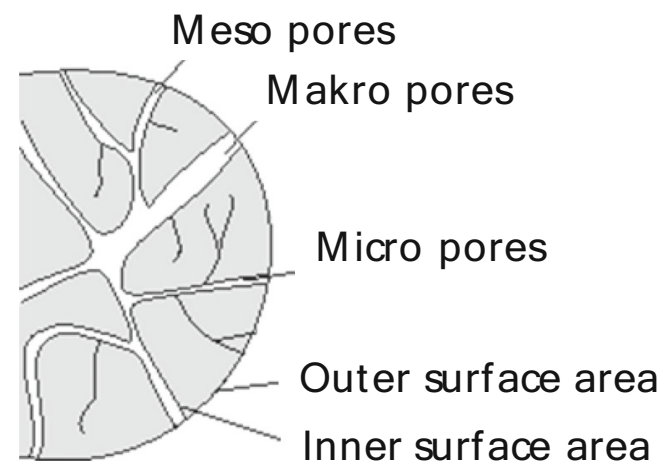

Fig. 6 Surface structure of adsorbent material in the post-reforming unit. This led to an increase of the share of meso pores and the pore volume in total [33]. The latter improves the water holding capacity of the char, because the diameters in a range of $0.1-10 \mu \mathrm{m}$ can retain the plant available water [34]. This is an additional benefit, if the biochar is used in soil. However, this effect has to be validated with other feedstock as well. The pore volume can be decreased with an increasing operating temperature, because of deformation of the porous structure, for instance [31].

\subsection{Heavy metals and organic pollutants}

During the thermochemical conversion of biomass in the absence of oxygen, organic pollutants can be formed. At a temperature above $500{ }^{\circ} \mathrm{C}$, hydrocarbon radicals are generated and build polyaromatic ring structures. Typical substances are polycyclic aromatic hydrocarbons (PAH) and polychlorinated biphenyls (PCB). These substances can condensate on the surface of the biochar while passing through the reactor [30,35]. Therefore, it is important to separate the vapor phase from the solid phase above the dew point of the

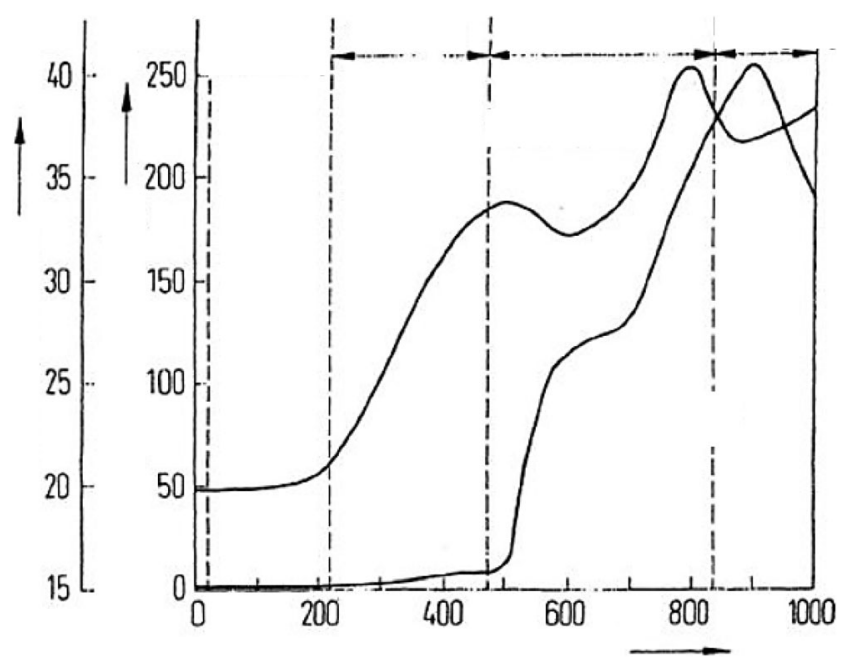

Fig. 7 Pore volume and surface area of lignite depending on process temperature [32] (adapted) 
Fig. 8 Pore size distribution of TCR®-biochar derived from digestate [33]

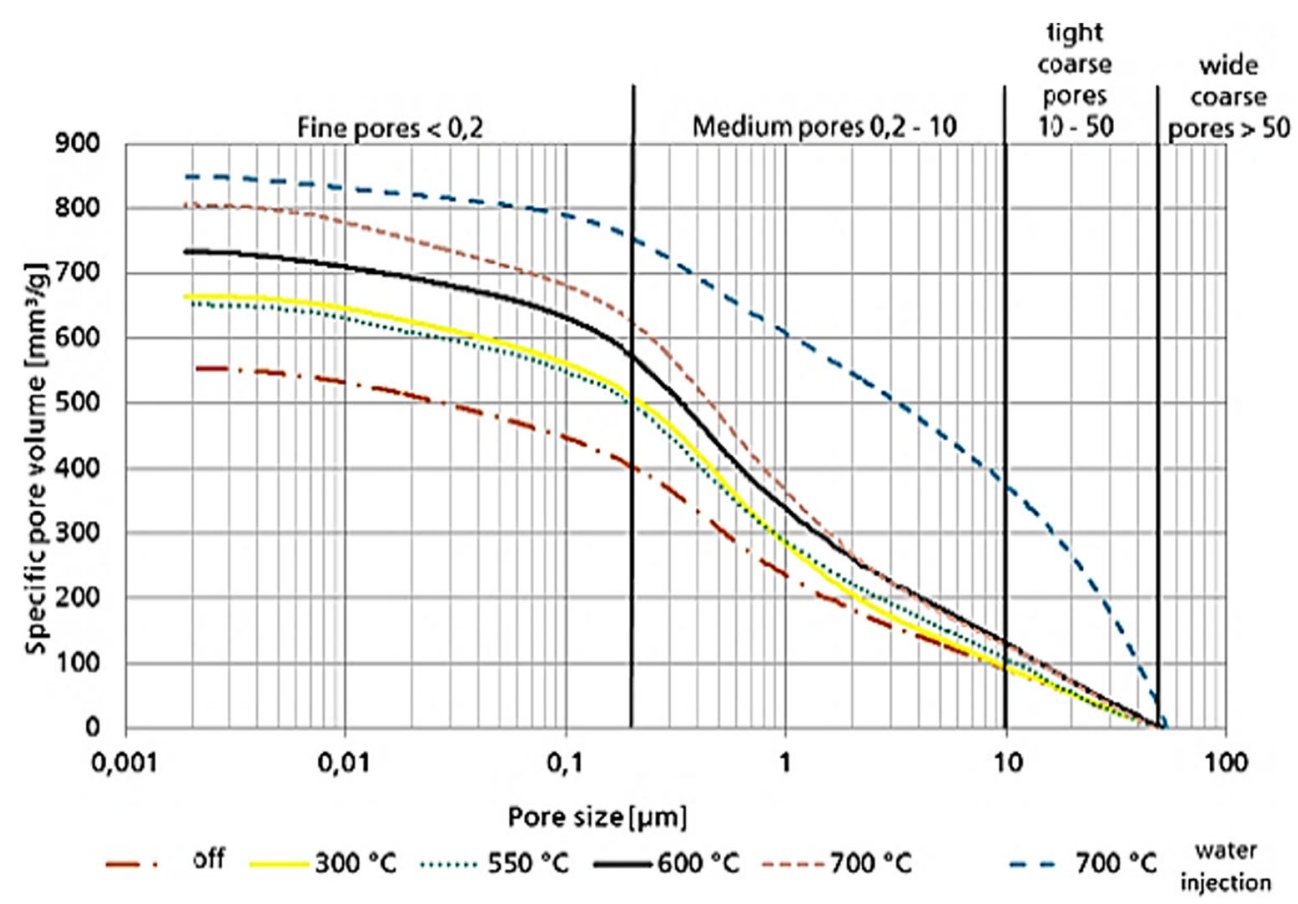

organic pollutants. Experiments have shown that with increasing operating temperature, the content of organic pollutants on chars increases for HTC and pyrolysis [36, 37], whereas for chars from TCR $\AA$, the content of organic pollutants decreases with an increase of the operating temperature in the postreforming step. Also pharmaceutical residues are thermally destroyed during TCR $®$-process if these compounds are present in the feedstock, like it might be the case for sewage sludge, for instance [20].

The heavy metal content in biochar is mainly influenced by the feedstock, because almost all heavy metals which are present in the feedstock remain in the char. Only volatile components like mercury or some heavy metal chlorides of lead, cadmium, and others can be transferred to the gaseous phase during the conversion process. Experiments with sewage sludge and the char derived from it have shown that the bioavailability of heavy metals decreases during pyrolysis [38]. However, if the biochar shall be used as a soil improver, for example, the relevant legal regulations have to be proved regarding conformity. Analysis of biochars derived from digestate from biogas plants has shown that legal regulations regarding heavy metals and organic pollutants content are fulfilled [28].

\section{Application of biochar}

\subsection{Framework conditions}

For each of the following applications, different legal regulations, certificates, or standards exist to ensure the quality for each application. That gives security to the user regarding suitability, health, and environment.

\subsubsection{Soil improver}

If biochar is used as a soil improver, the fertilizer regulation has to be applied. On European level, the fertilizer regulation was amended in 2019. The previous version from 2003 contained only mineral fertilizer. Therefore, one objective of the amendment was the extension to organic fertilizers. However, recycling products like biochar, ashes, and struvite from phosphorous recovery were not implemented. In 2020, three further component material categories (CMC) should be added, but this is not yet happening. One, CMC 14, would be for "pyrolysis and gasification materials." The CMCs are the allowed input materials for fertilizer production on European level.

Long time before the legislators considered biochar as a soil improver, biochar certificates were developed to define quality standards. The first one was established by the International Biochar Initiative (IBI) in the USA and Canada. They developed the "IBI Standardized Product Definition and Product Testing Guidelines for Biochar That is Used in Soil" which contains quality criteria for biochar production. The last revision was in 2015 [39]. In Europe, the European Biochar Certificate (EBC) is established. It was developed by the Ithaka Institute in Switzerland in 2010. They developed a guideline for biochar production analogous to IBI. The socalled Guidelines of the European Biochar Certificate were revised last time in 2019. In Switzerland the 
application of the EBC is mandatory [40]. The newest certificate that is the so-called Australian New Zealand Biochar Initiative (ANZBI) was established in 2017. It is based on the certificates of IBI and EBC and is applied in Australia and New Zealand. The following table shows quality requirements of IBI and $\mathrm{EBC}$, whereas for $\mathrm{EBC}$, two product categories exist-basic and premium (Table 3).

\subsubsection{Feed additive}

The EBC implemented also the certification of biochar as a feed additive in their guidelines in 2019. The bases are the quality standards of the premium category. Additional to that, stricter thresholds for organic pollutants and heavy metals were developed (see Table 4).

In addition to $\mathrm{EBC}$, a certification in accordance to GMP+ (Good Manufacturing Practice) is possible. For $\mathrm{GMP}+$ certification, the whole process chain is audited from feedstock to conversion, storage, and transport. There is basically no limitation regarding applied feedstock, but all commercial GMP+ certified feed additives based on biochar are derived from untreated wood. An extract of thresholds for pollutants in accordance to GMP+ is listed in Table 4 as well.

\subsubsection{Activated carbon}

Requirements for the application of biochar as activated carbon are listed in European standards like EN 12903 for powdered activated carbon and EN 12915 for granular activated carbon. Both standards are for activated carbon, which is used for treatment of potable water. The requirements listed in the standards are the ash content limited to $15 \mathrm{wt} \%$, the maximum water content of $5 \mathrm{wt} \%$, and the share of water extractable components with a maximum of $3 \mathrm{wt} \%$, for instance. In addition, thresholds for heavy metals and PAH are listed as well (see Table 5). As educt for the production of activated carbon, basically any carbon containing raw materials can be used. This includes materials like coconut shells, wood, peat, or coal.

\subsection{Market survey for biochar}

The broad range of possible applications for biochar shows the manifoldness of that black porous material. However, the three types of applications mentioned above are very promising. The markets are growing, and obtainable prices are high.

The price for biochar as a soil improver ranges from 200 to $2000 € / \mathrm{t}$. The high variety of the price is influenced by the quality of the biochar and the current market situation [44]. In Europe the biochar market will increase from about 0.31
Table 3 Quality criteria of IBI and $\mathrm{EBC}$ (extract) [41, 42]

\begin{tabular}{lllll}
\hline Parameter & Unit & EBC basic & EBC premium & IBI \\
\hline Carbon & wt\% & $>50$ & $>50$ & Class $1:>60$ \\
& & & Class 2: $>30$ \\
& & & $<0.7$ & Class 3: $>10$ \\
H/C & Mol/mol & $<0.7$ & $<0.4$ & $<0.7$ \\
O/C & Mol/mol & $<0.4$ & & n.a. \\
Thresholds for pollutants & & & 13 & $13-100$ \\
Arsenic & $\mathrm{Mg} / \mathrm{kg}$ & 13 & 120 & $121-300$ \\
Lead & $\mathrm{Mg} / \mathrm{kg}$ & 150 & 1 & $1,4-39$ \\
Cadmium & $\mathrm{Mg} / \mathrm{kg}$ & 1.5 & 80 & $93-1200$ \\
Chromium & $\mathrm{Mg} / \mathrm{kg}$ & 90 & - & $34-100$ \\
Cobalt & $\mathrm{Mg} / \mathrm{kg}$ & - & 100 & $143-6000$ \\
Copper & $\mathrm{Mg} / \mathrm{kg}$ & 100 & - & $5-75$ \\
Molybdenum & $\mathrm{Mg} / \mathrm{kg}$ & - & 30 & $47-420$ \\
Nickel & $\mathrm{Mg} / \mathrm{kg}$ & 50 & 1 & $1-17$ \\
Mercury & $\mathrm{Mg} / \mathrm{kg}$ & 1 & - & $2-200$ \\
Selenium & $\mathrm{Mg} / \mathrm{kg}$ & - & 400 & $416-7400$ \\
Zinc & $\mathrm{Mg} / \mathrm{kg}$ & 400 & 4 & $6-300$ \\
PAH (Sum 16 EPA) & $\mathrm{Mg} / \mathrm{kg}$ & 12 & 0.2 & $0,2-1$ \\
PCB & $\mathrm{Mg} / \mathrm{kg}$ & 0.2 & 20 & 17 \\
Dioxins (I-TEQ OMS) & $\mathrm{Ng} / \mathrm{kg}$ & 20 & 20 & 17 \\
Furans (I-TEQ OMS) & $\mathrm{Ng} / \mathrm{kg}$ & 20 & & \\
\hline & & & & \\
\hline
\end{tabular}


Table 4 Thresholds for pollutants in accordance to EBC and GMP+ $[41,43]$

\begin{tabular}{|c|c|c|c|}
\hline Parameter & Unit & EBC fodder* & $\begin{array}{l}\text { GMP+ } \\
\text { (extract) }\end{array}$ \\
\hline Arsenic & $\mathrm{Mg} / \mathrm{kg}$ & 2 & 2 \\
\hline Lead & $\mathrm{Mg} / \mathrm{kg}$ & 10 & 10 \\
\hline Cadmium & $\mathrm{Mg} / \mathrm{kg}$ & 1 & 1 \\
\hline Mercury & $\mathrm{Mg} / \mathrm{kg}$ & 0.1 & 0.1 \\
\hline Benzo-a-pyrene & $\mu \mathrm{g} / \mathrm{kg}$ & 25 & - \\
\hline Hexachlorobenzene (HCB) & $\mathrm{Mg} / \mathrm{kg}$ & - & 0.01 \\
\hline Sum of non-dioxin-like PCB & $\mu \mathrm{g} / \mathrm{kg}$ & - & 10 \\
\hline Fuorine & $\mathrm{Mg} / \mathrm{kg}$ & 150 & 150 \\
\hline Sum of dioxin and dioxin-like components & $\mathrm{Ng} / \mathrm{kg}$ & 1.25 & 1.25 \\
\hline $\mathrm{PCDD} / \mathrm{PCDF}$ & $\mathrm{Ng} / \mathrm{kg}$ & 0.75 & - \\
\hline Dioxin-like PCB & $\mathrm{Ng} / \mathrm{kg}$ & 0.35 & - \\
\hline DIN-PCB & $\mu \mathrm{g} / \mathrm{kg}$ & 10 & - \\
\hline
\end{tabular}

*Values referred to $88 \%$ dry matter billion US\$ in 2018 to 0.59 billion US\$ in 2023 [45]. This is an average growth rate of about $18 \%$ per year. The global market shows a more significant development. From 2018 to 2025, an increase of about 2.33 billion US\$ is expected [46]. This corresponds to a growth rate of about $22.5 \%$ per year.

Biochar used as feed additive is offered in big bags by many online shops in a range of about 1200 to $1750 € /$ t. However, for smaller containers, up to $5500 € / \mathrm{t}$ are charged. Because of the increasing number of suppliers, the demand to feed additives based on biochar seems to increase as well.

Activated carbon is offered in a range of about 700 to $1800 € /$ t. It depends on the quality and the market situation as well. The total market value is estimated on 2.35 billion US\$ in 2017. It is a rapidly increasing market. From 2017 to 2018 , the growth rate was about $20 \%$, and the market volume reached 2.81 billion US\$ in 2018 [47].

\section{Sustainable transportation fuels as a side product from TCR $^{\circledR}$}

Even if the markets for various biochar applications are growing and prices obtained are very promising, side products, like advanced biofuels, are needed to develop robust business cases. With the abovementioned Thermo-Catalytic Reforming process, two valuable side products, a hydrogenrich gas and a thermal-stable oil, can be produced. The mass balance of the TCR®-process at a reforming temperature of $500{ }^{\circ} \mathrm{C}$ with digestate as feedstock shows that $11 \%$ of the mass is converted into TCR $®$-oil, while $27 \%$ by mass is converted into hydrogen-rich gas with a hydrogen content of up to 45 Vol-\% [48]. The hydrogen-rich gas can be used for the supply of heat and power for the TCR®-process. As mentioned above, the TCR®-gas has a lower heating value of 13$18 \mathrm{MJ} / \mathrm{m}^{3}$ depending on the feedstock. Therefore, it can be
Table 5 Threshold for activated carbon in accordance to EN12903 and EN 12915

\begin{tabular}{lll}
\hline Parameter & Powdered activated carbon EN12903 & Granular activated carbon EN12915 \\
\hline Unit & Mg/kg DM & $\mu \mathrm{g} /$ i in extraction water \\
Antimony & 5 & 3 \\
Arsenic & 10 & 10 \\
Lead & 10 & 5 \\
Cadmium & 5 & 0.5 \\
Chrome & 50 & 5 \\
Nickel & 20 & 15 \\
Mercury & 1 & 0.3 \\
Selene & 10 & 3 \\
Cyanide & 50 & 5 \\
PAH & 0.2 & 0.02
\end{tabular}


Table 6 Comparison of TCR®oil composition to fast pyrolysis oil and biodiesel [22]

\begin{tabular}{|c|c|c|c|c|c|c|}
\hline Parameter & Unit & $\begin{array}{l}\text { TCR® sewage } \\
\text { sludge }\end{array}$ & $\begin{array}{l}\text { TCR } ® \\
\text { digestate }\end{array}$ & $\begin{array}{l}\text { TCR } ® \text { wood } \\
\text { chips }\end{array}$ & $\begin{array}{l}\text { Fast pyrolysis } \\
\text { wood }\end{array}$ & Biodiesel \\
\hline Carbon & $\mathrm{wt} \% *$ & 77.4 & 75.8 & 73.2 & 54.2 & 77.2 \\
\hline Hydrogen & $\mathrm{wt} \% *$ & 7.7 & 7.4 & 8.0 & 6.9 & 13.2 \\
\hline Nitrogen & $\mathrm{wt} \% *$ & 9.6 & 6.0 & 1.5 & 0.0 & 0.1 \\
\hline Sulfur & $\mathrm{wt} \% *$ & 0.8 & 1.9 & 0.3 & 0.0 & $<0.1$ \\
\hline Oxygen** & $\mathrm{wt} \% *$ & 4.5 & 8.9 & 17.0 & 38.9 & 9.4 \\
\hline Water & $\mathrm{wt} \%$ & 1.7 & 3.9 & 9.5 & 12.8 & $<0.1$ \\
\hline Ash & $\begin{array}{l}\mathrm{wt} \% \\
\text { (DM) }\end{array}$ & $<0.05$ & $<0.05$ & $<0.05$ & 0.4 & $<0.1$ \\
\hline HHV & $\begin{array}{l}\mathrm{MJ} / \mathrm{kg} \\
(\mathrm{DM})\end{array}$ & 35.6 & 35.6 & 35.3 & 20.1 & 39.3 \\
\hline TAN & $\mathrm{Mg}_{\mathrm{KOH}} / \mathrm{g}$ & 4.6 & 4.9 & 5.4 & $111-200$ & 2 \\
\hline
\end{tabular}

*Moisture and ash free basis

**Calculated by difference used in a combined heat and power plant (CHP) for additional economic benefit.

The various advantages of using the TCR®-oil are the lower oxygen and water content compared to other bio-oils as well as the most important characteristic, its thermal stability, which makes it distillable and applicable for other thermal processes. These properties offer various application options for the TCR $®$-oil. On the one hand, the oil can be converted to heat and power in a dual-fuel CHP and fed back into the TCR $®$-process. On the other hand, the TCR®-oil can also be used for the production of raw gasoline and ENcompliant diesel in conventional refinery. A further advantage of the TCR®-oil is the miscibility with fossil fuels. Therefore, direct application, for example, as a blend with fossil fuels, in any kind of combustion engines without any technical adaption is possible.
As described in Chapter 3.2, the TCR® is a two-step process based on intermediate pyrolysis followed by the reforming step of the created vapors during the intermediate pyrolysis. The level of development of the TCRß-process is the demonstration scale with a throughput of $500 \mathrm{~kg} / \mathrm{h}$. As previously described, the products obtained from a broad range of biomass feedstock by TCR $®$ process have unique properties compared to other thermochemical processes like fast pyrolysis [11, 22, 48, 49]. Table 6 shows the composition of TCRß-oil derived from various feedstocks compared to fast pyrolysis oil derived from wood and biodiesel.

It is shown that the elemental composition of TCR®-oil is close to biodiesel. Only nitrogen and sulfur need to be removed by hydrogenation. Also the heating value and the TAN are in the same range. In contrast, fast pyrolysis oil shows very different properties. Especially oxygen and water
Fig. 9 C-H-O ternary phase diagram [50]

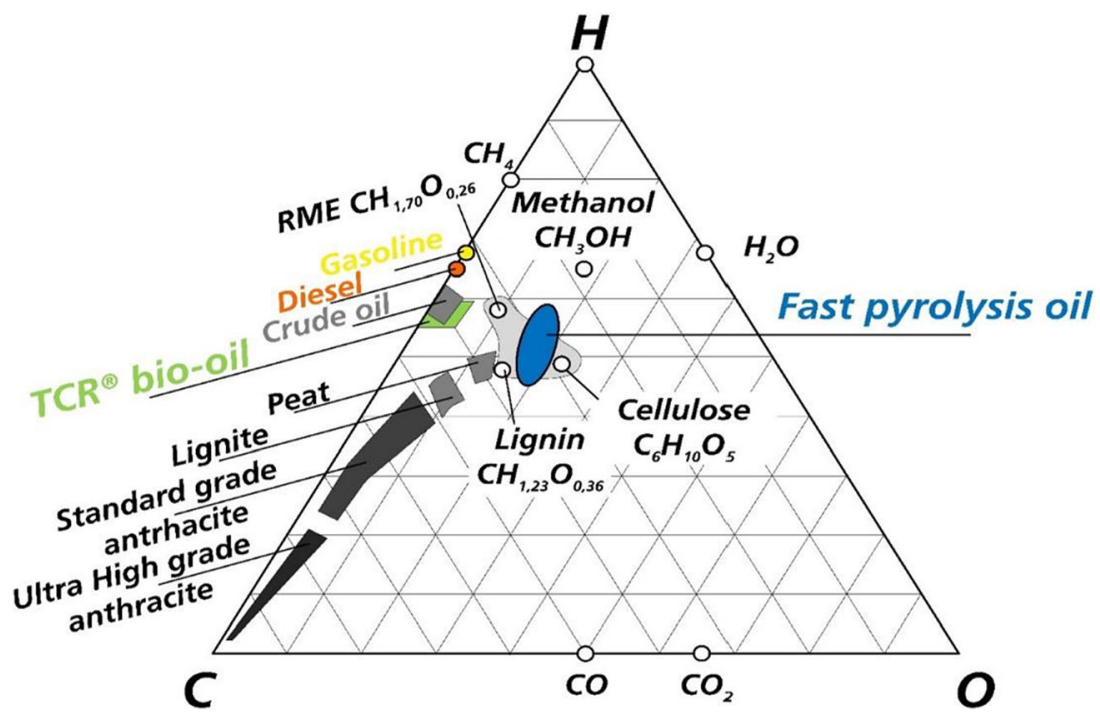


content as well as TAN are very high. Therefore, the energy content of the fast pyrolysis oil is quite low.

Regarding the $\mathrm{C}, \mathrm{H}$, and $\mathrm{O}$ contents, TCR $\AA$-oil is also comparable to fossil crude oil (see Fig. 9). Both, for TCR®oil and crude oil, the areas in the ternary diagram are almost completely overlapping, while fast pyrolysis oil is more in the area of the biomass components lignin and cellulose. Due to the similar properties of the TCR®-oil and fossil crude oil and the possibility to replace the fossil crude oil with TCR®-oil, similar values can be assumed for the economic considerations. The production of $1 \mathrm{t}$ of biochar results in $305 \mathrm{~kg}$ of TCR®-oil. The TCR®-oil produced increases the economics of biochar by $€ 0.45$ to $€ 0.50$ per kilogram.

\section{Conclusion}

Biochar is a carbon-enriched product from thermochemical conversion of biomass with a variety of properties and different qualities influenced by the type of feedstock and the applied production process. Therefore, it is not only one material; it is more a group of materials. Because of its diversity, it can be used for various applications. For these applications, the biochar is transformed to high-value products like soil improver, activated carbon, and feed additive. To ensure quality standards and safe application certificates, standards and legal regulations are developed. Only if the quality of the biochar for each application can be ensured, a market access is guaranteed.

The markets for biochar products have grown very fast within the recent years and achieved high market volumes. Therefore, biochar opens many opportunities for new business models. Furthermore, biochar contributes its part to mitigate the effects of climate change. Depending on its stability, the carbon, which was captured by the plants during the growth phase, is stored up to thousands of years in the char itself. This is caused by the low oxygen content in the char. In particular, biochars produced by TCR $®$ show the lowest oxygen contents compared to the other abovementioned processes which enables these long storage times.

Even if the markets for biochar applications are growing and obtainable prices are high, business cases are more robust if side products like the liquids from pyrolysis, for example, can be turned into valuable products as well. For TCR® with its thermal stable oil, for instance, EN standard fuels like gasoline and diesel can be obtained and therefore a further income generated. In addition, the fuels become $\mathrm{CO}_{2}$ negative, because of the carbon stored in the char.

This is different to the other processes shown. Oil obtained from fast pyrolysis with its high TAN and water content, for example, is not applicable as a substitute for fossil crude oil. From HTC no further side products are available. Some research is focusing on the recovery of valuable components from the HTC process water, but this is on an early stage.
Gasification and slow pyrolysis produce only a low calorific gas or respectively vapor phase. It can be used in a burner for heat production or after gas cleaning in a CHP for heat and power production.

If it is done right, the production of biochar combined with the use of side products like advanced biofuels can be the solution to mitigate problems of climate change. "So for the future of mankind, this black matter might give the light at the end of the tunnel."

Funding Open Access funding enabled and organized by Projekt DEAL.

Open Access This article is licensed under a Creative Commons Attribution 4.0 International License, which permits use, sharing, adaptation, distribution and reproduction in any medium or format, as long as you give appropriate credit to the original author(s) and the source, provide a link to the Creative Commons licence, and indicate if changes were made. The images or other third party material in this article are included in the article's Creative Commons licence, unless indicated otherwise in a credit line to the material. If material is not included in the article's Creative Commons licence and your intended use is not permitted by statutory regulation or exceeds the permitted use, you will need to obtain permission directly from the copyright holder. To view a copy of this licence, visit http://creativecommons.org/licenses/by/4.0/.

\section{References}

1. IPCC (2013) Ed. Climate change 2013: the physical science basis: Working Group I contribution to the Fifth assessment report of the Intergovernmental Panel on Climate Change; Cambridge University Press: Cambridge

2. Statista. Weltweiter CO2-Ausstoß in den Jahren 1960 bis 2018. https:/de.statista.com/statistik/daten/studie/37187/umfrage/derweltweite-co2-ausstoss-seit-1751/\#professional. Accessed 12 June 2020

3. Lehmann, J.; Joseph, S. Biochar for environmental management: an introduction. In: Biochar for environmental management: Science and technology. Lehmann, J., Joseph, S., Eds.; Earthscan: London, 2010; pp. 1-12.

4. Rajapaksha AU, Mohan D, Igalavithana AD, Lee SS, Ok YS (2016) Definitions and fundamentals of biochar. In: Ok Y-S, Uchimiya SM, Chang SX, Bolan N (eds) Biochar: Production, characterization, and applications. CRC Press Taylor \& Francis Group, Boca Raton, London, New York, pp 4-16

5. Haubold-Rosar M, Heinkele T, Rademacher A, Kern J, Dicke C, Funke A, Germer S, Karagöz Y, Lanza G, Libra J, Meyer-Aurich A, Mumme J, Theobald A, Reinhold J, Neubauer Y, Medick J, Teichmann I (2016) Chancen und Risiken des Einsatzes von Biokohle und anderer "veränderter" Biomasse als Bodenhilfsstoffe oder für die C-Sequestrierung in Böden. Dessau-Roßlau

6. Spokas KA (2010) Review of the stability of biochar in soils: predictability of O:C molar ratios. Carbon Management 1:289-303

7. Schmidt H-P (2012) 55 Uses of Biochar. ithaka Journal:286-289

8. Liu F, Peng H, You C, Fu Z, Huang P, Song H, Liao S (2014) Highperformance doped carbon catalyst derived from nori biomass with melamine promoter. Electrochimica Acta 138:353-359

9. Lehmann J, Gaunt J, Rondon M (2006) Bio-char sequestration in terrestrial ecosystems - a review. Mitig Adapt Strat Glob Change 11:403-427 
10. Brown R (2010) Biochar Production Technology. In: Lehmann J, Joseph S (eds) Biochar for environmental management: Science and technology. Earthscan, London, pp 127-146

11. Conti R, Jäger N, Neumann J, Apfelbacher A, Daschner R, Hornung A (2017) Thermocatalytic reforming of biomass waste streams. Energy Technol. 5:104-110

12. Thomé-Kozmiensky KJ (ed) (1998) Klärschlammentsorgung; TKVerl. Neuruppin, Thomé-Kozmiensky

13. Döhler H (ed) (2013) Faustzahlen Biogas. Darmstadt, KTBL

14. 25th European Biomass Conference and Exhibition.

15. LWF. Forsttechnik, Betriebswirtschaft, Holz: Lagerung und Trocknung. https://www.lwf.bayern.de/forsttechnik-holz/ holzverwendung/057596/index.php. Accessed December 10, 2020

16. Kambo HS, Minaret J, Dutta A (2018) Process water from the hydrothermal carbonization of biomass: a waste or a valuable product? Waste Biomass Valor 9:1181-1189

17. Blöhse D (2016) Karbonisate durch hydrothermale Verfahren. In: Quicker P, Weber K (eds) Biokohle. Springer Fachmedien Wiesbaden, Wiesbaden, pp 37-80

18. Büchler B (2012) HTC-Verfahren - die Vor- und Nachteile. Umwelt Perspektiven:26-27

19. Usman M, Chen H, Chen K, Ren S, Clark JH, Fan J, Luo G, Zhang $S$ (2019) Characterization and utilization of aqueous products from hydrothermal conversion of biomass for bio-oil and hydro-char production: a review. Green Chem. 21:1553-1572

20. Stenzel, F.; Jung, R.; Wiesgickl, S.; Dexheimer, K.; Eißing, M.; Mundt, M. Arzneimittelrückstände in Rezyklaten der Phosphorrückgewinnung: Abschlussbericht: Dessau-Roßlau, 2019.

21. Hornung A (2014) Pyrolysis. In: Hornung A (ed) Transformation of Biomass: Theory to Practice. Wiley, Hoboken, pp 99-112

22. Schmitt N, Apfelbacher A, Jäger N, Daschner R, Stenzel F, Hornung A (2019) Thermo-chemical conversion of biomass and upgrading to biofuel: the thermo-catalytic reforming process - a review. Biofuels, Bioprod Bioref 13:822-837

23. Jäger, N.; Neumann, J.; Apfelbacher, A.; Daschner, R.; Hornung, A. (2017) In: Conference proceedings, 25th European Biomass Conference and Exhibition, Stockholm, Schweden, 12.15.06.2017; ETA Florence, Ed.; pp. 1194-1197.

24. Baumbach G, Hartmann H, Höfer I, Hofbauer H, Hülsmann T, Kaltschmitt M, Lenz V, Neuling U, Nussbaumer T, Obernberger I, Schulze A-L, Wilk V, Winter F (2016) Grundlagen der Thermochemischen Umwandlung biogener Festbrennstoffe. In: Kaltschmitt M, Hartmann H, Hofbauer H (eds) Energie aus Biomasse. Springer Berlin Heidelberg, Berlin, Heidelberg, pp 579-814

25. van Loo S, Koppejan J (eds) (2009) The handbook of biomass combustion and co-firing. London, Earthscan

26. Weber K, Quicker P (2016) Eigenschaften von Biomassekarbonisaten. In: Quicker P, Weber K (eds) Biokohle. Springer Fachmedien Wiesbaden, Wiesbaden, pp 165-213

27. Krull, E.S.; Baldock, J.A.; Skjemstad, J.O.; Smernik, R.J. Characteristics of biochar: organo-chemical properties. In: Biochar for environmental management: Science and technology. Lehmann, J., Joseph, S., Eds.; Earthscan: London, 2010; pp. 53-65.

28. Stenzel F (2017) Biochar Quality Management: Alba, Italy, August 22, 2017

29. Ahlborn C, Wallmann R (2011) Stabilität unterschiedlich aufbereiteter Biomasse. Müll und Abfall:522-529

30. Mukome FND, Parikh SJ (2016) Chemical, physical, and surface characterization of biochar. In: Ok Y-S, Uchimiya SM, Chang SX, Bolan N (eds) Biochar: Production, characterization, and applications. CRC Press Taylor \& Francis Group, Boca Raton, London, New York, pp 67-96
31. Downie A, Crosky A, Munroe P (2010) Physical Properties of Biochar. In: Lehmann J, Joseph S (eds) Biochar for environmental management: Science and technology. Earthscan, London, pp 13-32

32. Benthaus F (1978) Rohstoff Kohle: Eigenschaften, Gewinnung, Veredelung. Verl. Chemie, Weinheim

33. Heberlein M (2017) Thermo-catalytic reforming (TCR) and TCRbiochar properties: Alba, Italy, August 22, 2017.

34. Liu C, Wang H, Tang X, Guan Z, Reid BJ, Rajapaksha AU, Ok YS, Sun $H$ (2016) Biochar increased water holding capacity but accelerated organic carbon leaching from a sloping farmland soil in China. Environmental science and pollution research international 23:995-1006

35. Camps M (2014) Polycyclic aromatic hydrocarbons and polychlorinated aromatic compounds in biochar: Santiago de Compostela, June 16, 2014

36. Dunnigan L, Morton BJ, van Eyk PJ, Ashman PJ, Zhang X, Hall PA, Kwong CW (2017) Polycyclic aromatic hydrocarbons on particulate matter emitted during the co-generation of bioenergy and biochar from rice husk. Bioresource Technol 244:1015-1023

37. Garlapalli RK, Wirth B, Reza MT (2016) Pyrolysis of hydrochar from digestate: effect of hydrothermal carbonization and pyrolysis temperatures on pyrochar formation. Bioresource Technol 220: 168-174

38. Lu T, Yuan H, Wang Y, Huang H, Chen Y (2016) Characteristic of heavy metals in biochar derived from sewage sludge. J Mater Cycles Waste Manag 18:725-733

39. IBI. Homepage. https://biochar-international.org/. Accessed April 3, 2020

40. EBC. Homepage. http://www.european-biochar.org/en/home

41. Hans-Peter Schmidt (2019) European Biochar Certificate (EBC) guidelines version 6.1 (version 8.3E)

42. IBI (2015) Standardized Product Definition and Product Testing Guidelines for Biochar that is Used in Soil: version 2.1

43. GMP+. Spezifische Grenzwerte für unbedenkliche Futtermittel: GMP+ BA1; Version DE, December 13, 2018.

44. Baumgarten A, Bohner A, Bruckmann VJ, Dunst G, Friesl-Hanl W, Greutter G, Höltinger S, Hofmann T, Hüffer T, Huber M, Hupfauf B, Keiblinger K, Kitzler B, Klinglmüller M, Kremser U, Mitterböck N, Moser A, Pfeifer C, Pfundtner E, Rech T, Schindecker SM, Schmid E, Schragner S, Sigmund G, Soja G, Spiegel H, Spann C, Wallner RM, Zehetner F (2017) Biokohle - Potential und Grenzen der Anwendung in der Land- und Forstwirtschaft: Wien, August 01, 2017.

45. Market Data Forecast. Europe Biochar Market by Type and Size: Industry Report 2018-2023. https://www.marketdataforecast.com/ market-reports/europe-biochar-market. Accessed 30 July 2019

46. Zion Market Research. Global biochar market will reach to USD 3.82 billion by 2025. www.globenewswire.com (Accessed July 30, 2019).

47. OEC World. Activated Carbon. https://oec.world/en/profile/hs92/ 63802/. Accessed 17 June 2020

48. Neumann J, Binder S, Apfelbacher A, Gasson JR, Ramírez García $\mathrm{P}$, Hornung A (2015) Production and characterization of a new quality pyrolysis oil, char and syngas from digestate - introducing the thermo-catalytic reforming process. Journal of Analytical and Applied Pyrolysis 113:137-142

49. Neumann J, Jäger N, Apfelbacher A, Daschner R, Binder S, Hornung A (2016) Upgraded biofuel from residue biomass by thermo-catalytic reforming and hydrodeoxygenation. Biomass and Bioenergy 89:91-97

50. Hornung A (2019) EN-Fuels from solid waste biomass by thermocatalytic reforming: cork, June 16th - 20th, 2019.

Publisher's note Springer Nature remains neutral with regard to jurisdictional claims in published maps and institutional affiliations. 